Article

\title{
Synthesis and Antiplasmodial Activity of Betulinic Acid and Ursolic Acid Analogues
}

Adrine M. Innocente ${ }^{1}$, Gloria N. S. Silva ${ }^{1}$, Laura Nogueira Cruz ${ }^{2}$, Miriam S. Moraes ${ }^{2}$, Myna Nakabashi ${ }^{2}$, Pascal Sonnet ${ }^{3}$, Grace Gosmann ${ }^{1}$, Célia R. S. Garcia ${ }^{2}$ and Simone C. B. Gnoatto ${ }^{1, *}$

1 Laboratório de Fitoquímica e Síntese Orgânica, Faculdade de Farmácia, Programa de Pós-Graduação em Ciências Farmacêuticas, Universidade Federal do Rio Grande do Sul. Av. Ipiranga, 2752, Porto Alegre 90610-000, RS, Brazil; E-Mails: a_innocente@yahoo.com.br (A.M.I.); glorianarjara@yahoo.com.br (G.N.S.S.); grace.gosmann@ufrgs.br (G.G.)

2 Laboratório de Biologia Celular e Molecular de Plasmodium, Departamento de Fisiologia, Instituto de Biociências, Universidade de São Paulo, USP. Rua do Matão, travessa 14, 321, São Paulo 05508-900, SP, Brazil; E-Mails: laurancruz@ gmail.com (L.N.C.); miradun@yahoo.com.br (M.S.M.); mnakab@ib.usp.br (M.N.); cgarcia@usp.br (C.R.S.G.)

3 Laboratoire des Glucides, FRE CNRS 3517, UFR de Pharmacie Université de Picardie Jules Verne1, Rue des Louvels, 80037 Amiens cedex 1, France

* Author to whom correspondence should be addressed; E-Mail: simone.gnoatto@ufrgs.br; Tel.: +55-51-3308-5451; Fax: +55-51-3308-5313.

Received: 17 September 2012; in revised form: 24 September 2012 / Accepted: 7 October 2012 / Published: 12 October 2012

Abstract: More than $40 \%$ of the World population is at risk of contracting malaria,
which affects primarily poor populations in tropical and subtropical areas. Antimalarial
pharmacotherapy has utilised plant-derived products such as quinine and artemisinin as
well as their derivatives. However, worldwide use of these antimalarials has caused the
spread of resistant parasites, resulting in increased malaria morbidity and mortality.
Considering that the literature has demonstrated the antimalarial potential of triterpenes,
specially betulinic acid (1) and ursolic acid (2), this study investigated the antimalarial
activity against $P$. falciparum chloroquine-sensitive $3 \mathrm{D} 7$ strain of some new derivatives of $\mathbf{1}$
and 2 with modifications at C-3 and C-28. The antiplasmodial study employed flow
cytometry and spectrofluorimetric analyses using YOYO-1, dihydroethidium and
Fluo4/AM for staining. Among the six analogues obtained, compounds $\mathbf{1 c}$ and $\mathbf{2 c}$ showed
excellent activity $\left(\mathrm{IC}_{50}=220\right.$ and $175 \mathrm{nM}$, respectively) while $\mathbf{1 a}$ and $\mathbf{b}$ demonstrated good 
activity ( $\mathrm{IC}_{50}=4$ and $5 \mu \mathrm{M}$, respectively). After cytotoxicity evaluation against HEK293T cells, 1a was not toxic, while $1 \mathrm{c}$ and $\mathbf{2 c}$ showed $\mathrm{IC}_{50}$ of $4 \mu \mathrm{M}$ and a selectivity index (SI) value of 18 and 23, respectively. Moreover, compound 2c, which presents the best antiplasmodial activity, is involved in the calcium-regulated pathway(s).

Keywords: triterpenes; betulinic acid; ursolic acid; malaria; P. falciparum; cytotoxicity; calcium

\section{Introduction}

Malaria is responsible for some 216 million clinical cases and 655,000 deaths annually, especially among children and pregnant women [1]. Due to the spread of resistant parasites, the development of new medicines is imperative for the control and eradication of malaria [2].

Among the first antimalarial substances, the cinchona alkaloids (such as quinine and quinidine) were shown to arrest the development of malignant tertian malaria parasites. Subsequently, the sesquiterpene lactone artemisinin was obtained from Artemisia annua, and became very important for the control of malarial infection, resulting in the development of more potent derivatives, such as artemether and artesunate [3]. Thus the partnership between medicinal and natural products chemistry is an important strategy in innovative drug discovery [4,5]. In this sense, the chemical modification of natural products having antimalarial activities may be one promising method for developing more effective and less toxic antimalarial drugs.

Many studies regarding triterpenes and their derivatives possessing antimalarial activity which highlight two triterpenes, betulinic and ursolic acids, are reported [6-10]. For example, Ziegler and co-workers described the anti-Plasmodium activity on the 3D7 strain of betulinic acid and its analogues and reported that treatment with these compounds resulted in modified erythrocyte membranes. While betulinic acid was active, with an $\mathrm{IC}_{50}$ value of $13.9 \mu \mathrm{M}$, the most active analogue was methyl betulinate $\left(\mathrm{IC}_{50} 7 \mu \mathrm{M}\right)$ [7]. However, in a murine malarial model of $P$. berghei betulinic acid was ineffective at $250 \mathrm{mg} / \mathrm{kg} /$ day [6]. We developed some piperazinyl derivatives of ursolic acid obtaining three antimalarial compounds potent against the $P$. falciparum chloroquine-sensitive Thai strain, including compound 2c possessing an $\mathrm{IC}_{50}$ value of $167 \mathrm{nM}$ [10] (Figure 1). Moreover, we could demonstrate the importance of the triterpene skeleton bearing an acetyl group at C-3 and the piperazine moiety was also identified as a pharmacophore.

These derivatives were designed based on studies reporting that piperazine derivatives have antimalarial action [11,12]. For example, a series of bisacridine derivatives coupled with bisaminopropylpiperazine were found to have significant antimalarial effects when tested in vitro for antimalarial activity against the P. falciparum chloroquine-resistant FcB1R strain [11]. 
Figure 1. Strategy used to obtain $N$-\{3-[4-(3-aminopropyl)piperazinyl]propyl $\}-3-O$ acetylursolamide derivatives as antimalarial agents.

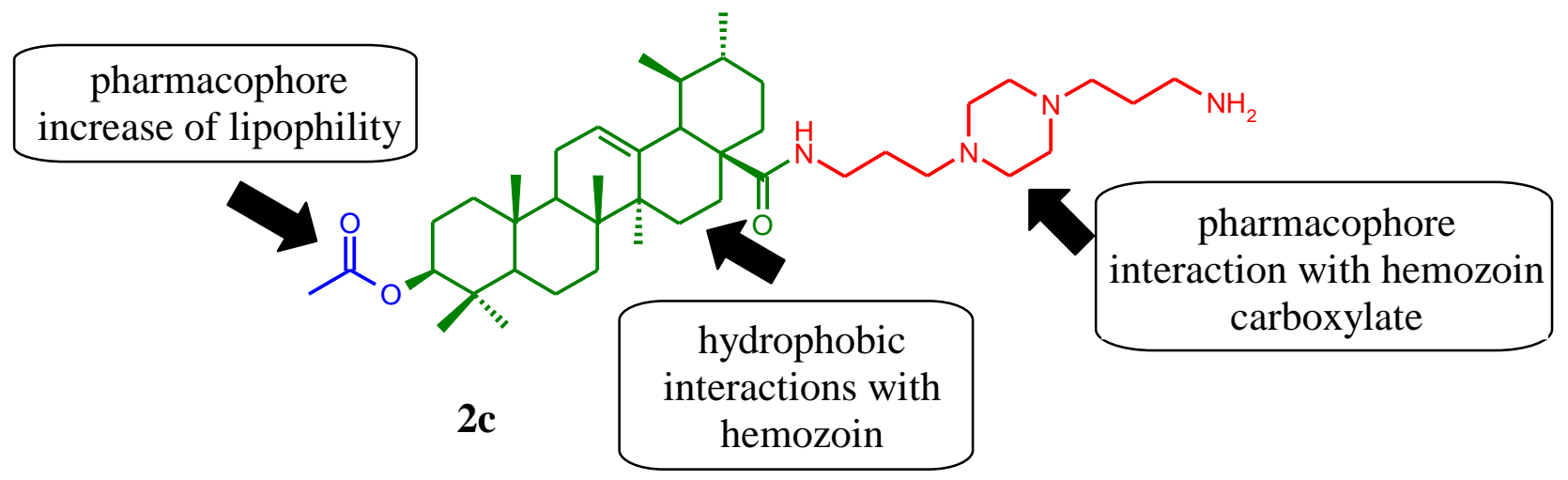

Until the moment little is known about mechanism of action for triterpenes, with reports for hematin and modification at erythrocyte membrane actions. [7,10]. Because $\mathrm{Ca}^{2+}$ homeostasis and signalling are fundamental for parasite survival [13-15], the mechanism involved in calcium homeostasis within malaria parasites has been investigated as a potential target against malaria [16].

In continuation of our research, the present study investigated new piperazinyl derivatives at C-28 of acetyl betulinic acid (compounds 1a-c) comparing them with those of the ursolic acid (compounds $\mathbf{2 a - c )}$ as prototypes for new antimalarial compounds against the $P$. falciparum chloroquine-sensitive 3D7 strain. Further the cytotoxicity in vitro was estimated and a novel antimalarial mechanism of action for triterpenes was also revealed.

\section{Results and Discussion}

\subsection{Chemical Synthesis}

After being isolated from natural sources, the importance of the C-3 hydroxyl group of betulinic and ursolic acids $\mathbf{1}$ and $\mathbf{2}$ was ascertained through usual acetylation (Scheme 1). The acetylated compounds numbered 1a and 2a were obtained in $98 \%$ yield. The coupling reaction of $\mathbf{1 a}$ and $\mathbf{2 a}$ with $N$-tertbutoxycarbonyl-1,4-bis(3-aminopropyl)piperazine occurred following activation of the carboxylic acid at C-17 with oxalyl chloride as previously described [10]. The corresponding derivatives $\mathbf{1 b}$ and $\mathbf{2 b}$ were then isolated in $80 \%$ yield. Treatment with $10 \%$ trifluoroacetic acid/dichloromethane removed the tert-butoxycarbonyl (Boc) to provide compounds 1c and 2c in $70 \%$ yield (Scheme 1). All compounds were fully characterised by spectroscopic data.

\subsection{Antiplasmodial Assay}

All compounds were evaluated in vitro against the $P$. falciparum chloroquine-sensitive 3D7 strain in comparison to chloroquine which $\mathrm{IC}_{50}$ value was $29 \mathrm{nM}$. Compound 1 showed moderate activity $\left(\mathrm{IC}_{50} 18 \mu \mathrm{M}\right)$ and 2 was inactive ( $\mathrm{IC}_{50} 36 \mu \mathrm{M}$ ) (Figure 2, Table 1) which results are in agreement with those of the literature $[6,17,18]$. 
Acetylated derivatives 1a and 2a showed better antimalarial activity than their aglycones ( $\mathrm{IC}_{50}$ values of 4 and $14 \mu \mathrm{M}$, respectively) (Figure 2, Table 1). The highest values were obtained for the piperazinyl derivatives $\mathbf{1 c}\left(\mathrm{IC}_{50} 220 \mathrm{nM}\right)$ and $\mathbf{2 c}\left(\mathrm{IC}_{50} 175 \mathrm{nM}\right)$. Protected compounds $\mathbf{1 b}$ and $\mathbf{2 b}$ presented $\mathrm{IC}_{50}$ values of 5 and $15 \mu \mathrm{M}$, respectively, demonstrating a lower capacity to reduce parasitemia in comparison to unprotected compounds. As shown in Figure 2, the piperazine group contributed to a significant improvement in activity as also reported [19].

Scheme 1. Synthesis of $N$-\{3-[4-(3-aminopropyl)piperazinyl]propyl $\}-3-O$-acetyl betulinamides $\mathbf{1 a}-\mathbf{c}$ and $N$-\{3-[4-(3-aminopropyl)piperazinyl]propyl $\}-3-O$-acetylursolamides $\mathbf{2 a - c}$.

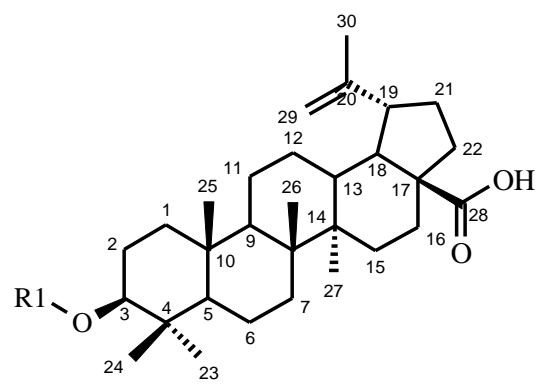

$\mathrm{i}\left[\begin{array}{cc}\mathbf{1} & \mathrm{R} 1=\mathrm{H} \\ \mathbf{1} \mathbf{1 a} & \mathrm{R} 1=\mathrm{Ac}\end{array}\right.$

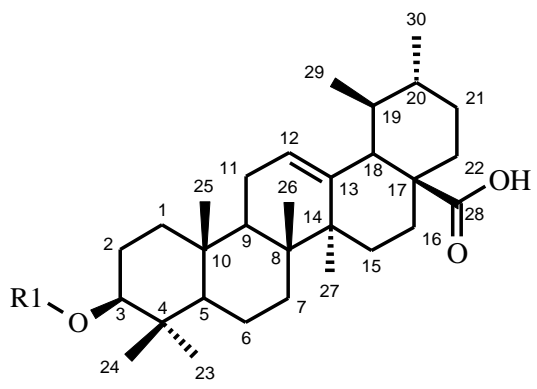

$\mathrm{i}\left[\begin{array}{cc}2 & \mathrm{R} 1=\mathrm{H} \\ \mathbf{2} & \mathrm{a} \\ \mathrm{R} 1=\mathrm{Ac}\end{array}\right.$

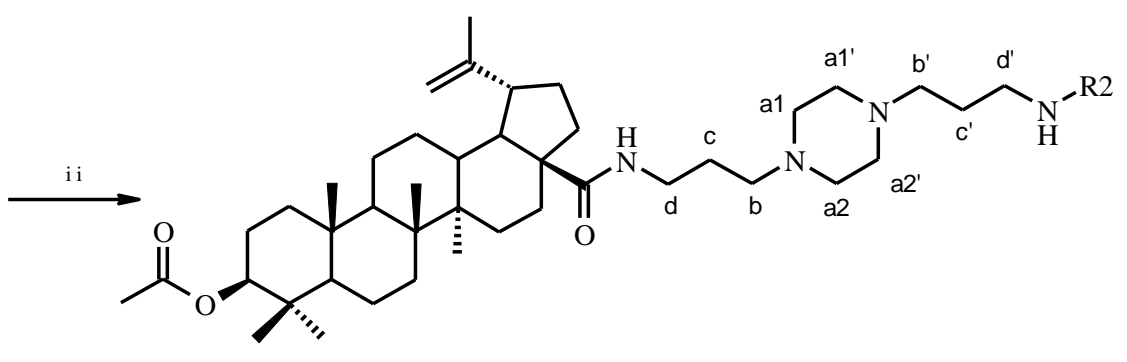

iii $\left[\begin{array}{ll}1 \mathrm{~b} & \mathrm{R} 2=\mathrm{Boc} \\ \rightarrow 1 \mathrm{c} & \mathrm{R} 2=\mathrm{H}\end{array}\right.$<smiles>[R2]NCCCN1CCN(CCCNC(=O)[C@@]23CC[C@H](C)[C@@H](C)C2C2=CC[C@@H]4[C@](C)(CC[C@@H]5C(C)(C)[C@@H](OC(C)=O)CC[C@@]54C)[C@@]2(C)CC3)CC1</smiles>

iii $\left[\begin{array}{rr}2 \mathbf{b} & \mathrm{R} 2=\mathrm{Boc} \\ \mathbf{2 c} & \mathrm{R} 2=\mathrm{H}\end{array}\right.$

Reagents and conditions: (i) pyridine, acetic anhydride, RT, $24 \mathrm{~h}$; (ii) $\mathrm{ClCOCOCl}, 0{ }^{\circ} \mathrm{C}, 3 \mathrm{~h}$; TEA, $N$-tert-butoxycarbonyl-1,4-bis(3-aminopropyl)piperazine, RT, 24 h; (iii) TFA 10\%/ $\mathrm{CH}_{2} \mathrm{Cl}_{2}, \mathrm{RT}, 6 \mathrm{~h}$.

\subsection{Cytotoxicity Assay}

The active derivatives $\mathbf{1 a - c}$ and $\mathbf{2 c}$ were evaluated for their cytotoxicity in human embryonic kidney cells (HEK293T) by monitoring the number of living cells at the same concentrations used to evaluate the antiplasmodial activity $(100,10,1,0.1,0.01$ and $0.001 \mu \mathrm{M})$. Many research groups have tried to find cytotoxicity activity from triterpenoids, including betulinic acid and their derivatives. Thibeault et al. presented cytotoxicity results of lupane-type triterpenoid glyceryl esters. Betulinic acid showed values of 18 to $57 \mu \mathrm{M}$ in several cell lines [20]. 
Figure 2. Drug concentration response curves of betulinic and ursolic acid acetylated derivatives $\mathbf{1 a}$ and $\mathbf{2 a}$, coupled $\mathbf{1 b}$ and $\mathbf{2 b}$ and deprotected piperazinyl derivatives $\mathbf{1 c}$ and 2c against the chloroquine-sensitive $P$. falciparum strain 3D7 strain. The results are representative of three independent experiments $(n=3)$.
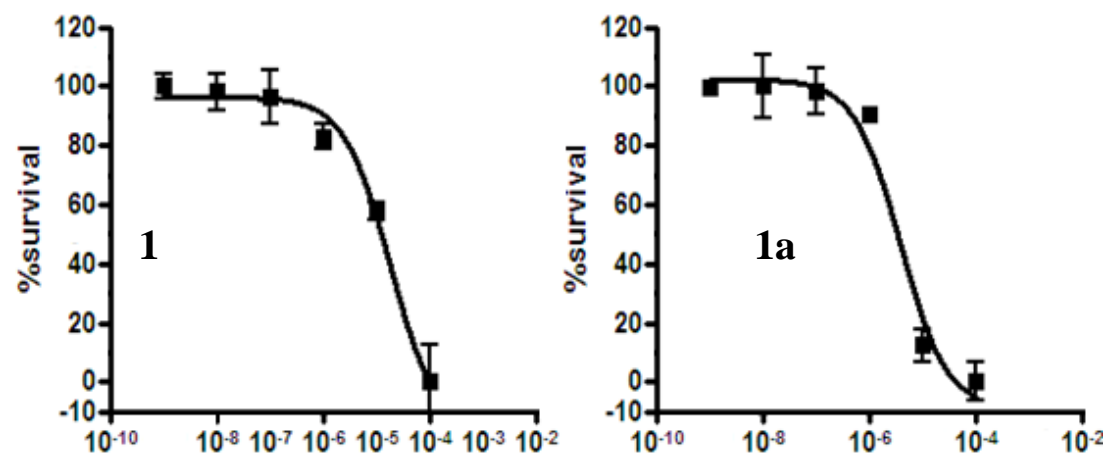

[ ] M
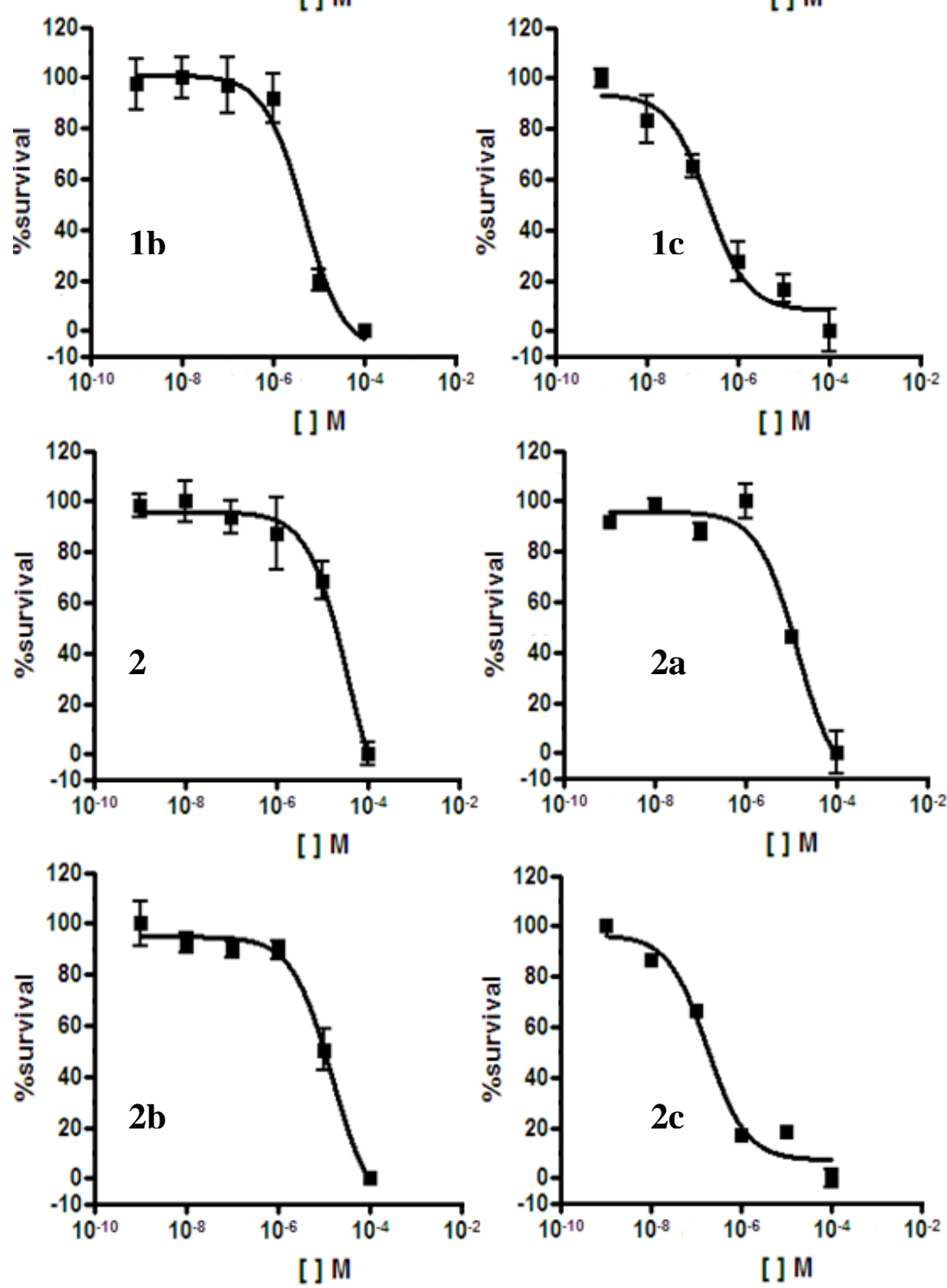
Table 1. Antiplasmodial and cytotoxic activity of compounds $\mathbf{1}, \mathbf{1 a}-\mathbf{c}$ and $\mathbf{2}, \mathbf{2 a}-\mathbf{c}$. The results are representative of three independent experiments $(n=3)$.

\begin{tabular}{|c|c|c|c|c|}
\hline \multirow[t]{2}{*}{ Compounds } & \multirow{2}{*}{$\begin{array}{c}\mathrm{IC}_{50}(\mu \mathrm{M}) \\
\text { P. falciparum 3D7 }\end{array}$} & \multicolumn{2}{|c|}{$\begin{array}{l}\mathrm{IC}_{50}(\mu M) \\
\text { HEK293T }\end{array}$} & \multirow{2}{*}{$\begin{array}{l}\text { Selectivity Index (SI) } \\
48 \mathrm{~h}\end{array}$} \\
\hline & & $24 \mathrm{~h}$ & $48 \mathrm{~h}$ & \\
\hline 1 & 18 & - & - & - \\
\hline $1 \mathrm{a}$ & 4 & $>100$ & $>100$ & - \\
\hline $1 b$ & 5 & 4 & 4 & 0.8 \\
\hline $1 \mathrm{c}$ & 0.220 & 4 & 4 & 18 \\
\hline 2 & 36 & - & - & - \\
\hline $2 a$ & 14 & - & - & - \\
\hline $2 b$ & 15 & - & - & - \\
\hline $2 \mathrm{c}$ & 0.175 & 4 & 4 & 23 \\
\hline
\end{tabular}

On the other hand, the cytotoxicity of heterocyclic triteprenoids derived from betulin and betulinic acid was tested against seven tumor and two normal fibroblast cell lines showing activity values from 1.0 to $55.5 \mu \mathrm{mol} / \mathrm{L}$ [21]. The results displayed in Table 1 show that $\mathbf{1 a}$ was not cytotoxic at the tested concentrations, while the piperazinyl derivatives $\mathbf{1 b}, \mathbf{c}$ and $\mathbf{2 c}$ showed $\mathrm{IC}_{50}$ values of $4 \mu \mathrm{M}$. Moreover, the most active compounds $1 \mathbf{c}$ and $\mathbf{2 c}$ presented SI values of 18 and 23, respectively, being considered non-toxic.

\subsection{Infected Erythrocytes: Loading with the Calcium Indicator Fluo4/AM}

Like most eukaryotic cells, malaria parasites have internal $\mathrm{Ca}^{2+}$ pools responsible for regulation of signalling processes during invasion, maturation and division that can be mobilised upon agonist stimulation in the plasma membrane [22]. The effect of compound 2c through modulation of one or more calcium pathways in $P$. falciparum (3D7) was demonstrated using the fluorescent calcium probe Fluo4/AM. This molecule was chosen because it has the highest selectivity index (23, Table 1).

The typical rise in cytosolic calcium in isolated parasites after addition of compound $2 \mathrm{c}(100 \mu \mathrm{M})$ and thapsigargin (THG) $(10 \mu \mathrm{M})$ is presented in Figure 3a-c. Because THG has been known to modulate $\mathrm{Ca}^{2+}$ via inhibition of sarco-endoplasmatic reticulum $\mathrm{Ca}^{2+}$ ATPase (SERCA) [23], it was used as the control in this experiment. The control experiment (with methanol addition) showed clearly that the solvent did not elicit calcium increase within the parasites (Figure 3a). On the contrary, when THG was added after compound $\mathbf{2 c}$, the calcium increase was greater than the conventional calcium mobilisation observed with the control one (Figure $3 b$ ). These results indicated that $\mathbf{2 c}$ can modulate parasite calcium homeostasis. 
Figure 3. Modulation of the Plasmodium calcium pathway(s) involved in the mechanism of action of compound 2c. Representative traces of the change in Fluo4/AM) fluorescence over time upon addition of solvent (a) or $2 \mathbf{c}(100 \mu \mathrm{M})(\mathbf{b})$ in P. falciparum followed by THG $(10 \mu \mathrm{M})$ addition. (c) Bar graph analysis of $\mathrm{Ca}^{2+}$ concentrations in Fluo4/AM-labelled $P$. falciparum isolated parasites $\left(10^{8}\right.$ cells $\left.\mathrm{mL}^{-1}\right)$ after addition of $2 \mathrm{c}(100 \mu \mathrm{M})$. Data presented (104.9 a.u. $\pm 13.65, \mathrm{n}=9, P=0.0004)$ were in $P$. falciparum. $P$ values $(*)$ were calculated by comparison with methanol $(0.05 \%)(1.46$ a.u. $\pm 0.057, \mathrm{n}=4)$. Bars represent the means and SEM values. The fluorescence was measured continuously (acquisition every $0.5 \mathrm{~s}$ ). The results are representative of three independent experiments performed in triplicate.

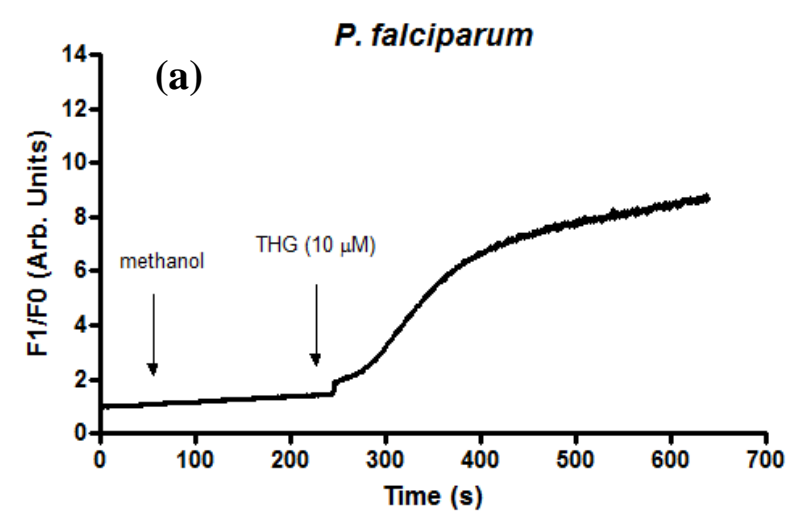

P. falciparum

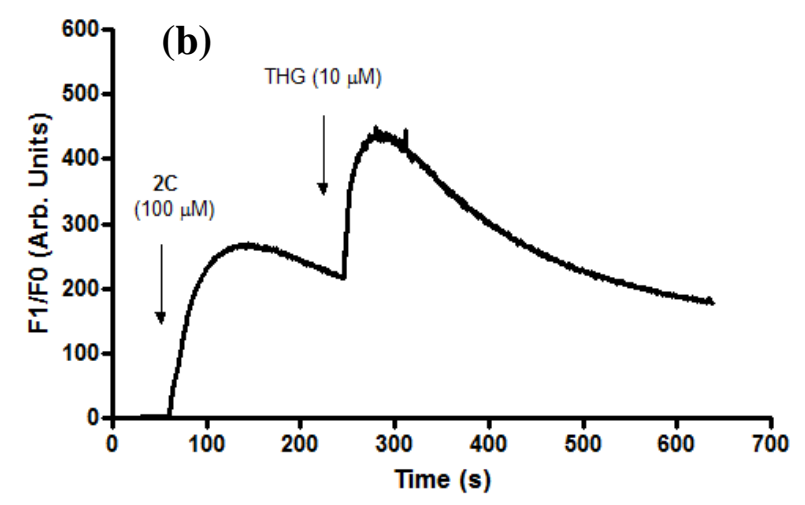

P. falciparum

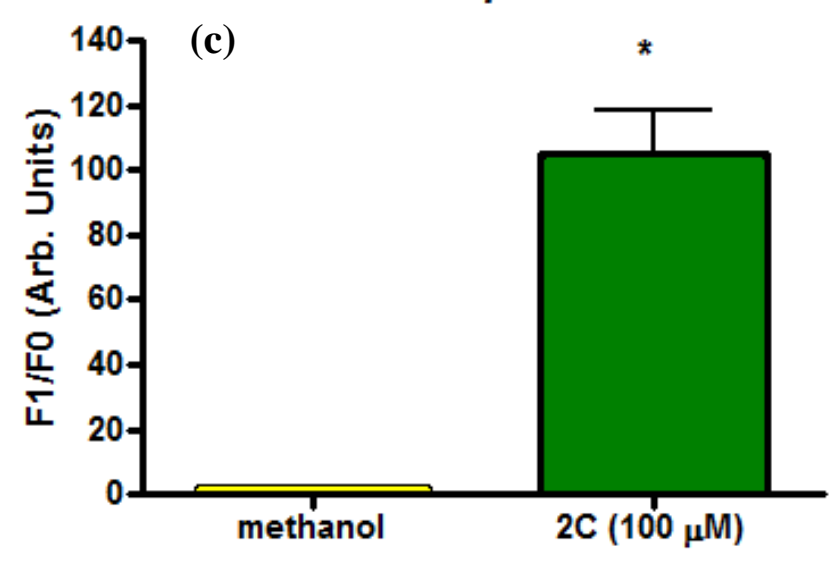




\section{Experimental}

\subsection{General}

Infrared spectra (IR) were obtained using a PerkinElmer FT-IR System Spectrum BX instrument. ${ }^{1} \mathrm{H}$ and ${ }^{13} \mathrm{C}$-NMR spectra were recorded on Varian Inova 300 and Varian VNMRS 300 spectrometers using TMS as internal standard. Chemical shifts are reported in parts per million ( $\delta)$. An UltrOTOF (BrukerDaltonics) mass spectrometer was used to obtain HR-EI-MS spectra. Melting points were determined using a Koffler instrument. All reactions were monitored by thin-layer chromatography on Merck silica plates GF using different solvent systems. Column chromatography was carried out on silica gel GF (Merck, 60-230 mesh) using gradient mixtures $\left(\mathrm{CH}_{2} \mathrm{Cl}_{2} /\right.$ methanol). All reagents were purchased as analytical grade. All solvents were dried and distilled prior use. Dichloromethane was dried over $\mathrm{CaCl}_{2}$ for $24 \mathrm{~h}$ then was submitted to reflux.

\subsection{Plant Material and Isolation of Triterpenes}

The betulinic acid was obtained from Platanus acerifolia. A voucher specimen (ICN 182537) is on deposit in the Botany Department Herbarium of Universidade Federal do Rio Grande do Sul, Porto Alegre, Brazil. The peel of Malus domestica was a byproduct from the juice industry company Tecnovin S.A., Vacaria, RS, Brazil, and was used to obtain the ursolic acid. Both powdered dried materials were separately subjected to reflux with ethanol $60 \%(250 \mathrm{~mL}, 2 \mathrm{~h})$. Then, after removing the ethanol under vacuum, each residual aqueous phase was separately extracted with ethyl acetate, and the organic phase was evaporated to dryness to obtain a residue that was submitted to recrystallisation. The betulinic acid was recrystallized from methanol, while ursolic acid was recrystallized using acetonitrile. Betulinic acid (1). Yield 1.5\%. Its structure was confirmed by spectroscopic methods which were in agreement with literature data [6,7]. Ursolic acid (2). Yield 4\%. Its structure was confirmed by spectroscopic methods and literature data [10].

\subsection{Chemical Synthesis}

The ursolic acid derivatives were prepared using a semisynthetic route developed by Gnoatto and co-workers which details of the chemistry and structural elucidation were described previously [10]. Briefly, the acetylated ursolic acid 2a was submitted to a coupling reaction with $N$-Boc-bisaminopropylpiperazine in basic conditions to obtain $\mathbf{2 b}$, and then the deprotected analogue 2c was obtained by removing the $N$-Boc-amino group. All structural assignments were compared with the published data [10]. The betulinic acid derivatives were obtained using an analogous route.

3-O-Acetylbetulinic acid (1a). Yield 98\%. It was prepared from the corresponding aglycone $\mathbf{1}$ by usual acetylation [10].

$\mathrm{N}$-\{3-[4-(3-Aminopropyl)piperazinopropyl]terbutylcarbamate\}-3-acetylbetulinamide (1b). Oxalyl chloride $(0.15 \mathrm{~mL}, 1.7 \mathrm{mmol})$ was added to $1 \mathbf{a}(285 \mathrm{mg}, 0.57 \mathrm{mmol})$ dissolved in $\mathrm{CH}_{2} \mathrm{Cl}_{2}(30 \mathrm{~mL})$ at $0{ }^{\circ} \mathrm{C}$, and the resulting solution was stirred under $\mathrm{N}_{2}$ for $3 \mathrm{~h}$. Subsequently, triethylamine $(0.5 \mathrm{~mL}, 3.4 \mathrm{mmol})$ and then tert-butyl 3-[4-(3-aminopropyl)piperazinylpropyl]carbamate $(510 \mathrm{mg}, 1.7 \mathrm{mmol})$ were added to the 
reaction, which was then stirred for $24 \mathrm{~h}$ at room temperature. Next, water was added and the resulting product was extracted with $\mathrm{CH}_{2} \mathrm{Cl}_{2}(3 \times 30 \mathrm{~mL})$; the organic layers were combined, dried over $\mathrm{Na}_{2} \mathrm{SO}_{4}$ and evaporated under vacuum to afford $\mathbf{1 b}$ as a white solid. Yield: $80 \%$; m.p. $129{ }^{\circ} \mathrm{C}$; IR (ATR cm ${ }^{-1}$ ): $3406(\mathrm{NH}) ; 2943(\mathrm{C}-\mathrm{H}) ; 1777$ (C=O acetyl); 1687 (C=O amide); 1555 (C=C); 1425 (C-O); $1380(\mathrm{C}-\mathrm{H})$; 1259 (C-O-C); 1176 (C-N). ${ }^{1} \mathrm{H}-\mathrm{NMR}\left(\mathrm{CDCl}_{3}, \delta\right): 0.84$ (s, 3H, $\left.\mathrm{H}_{26}\right) ; 0.85$ (s, 3H, $\mathrm{H}_{27}$ ); 0.87 (s, 3H, H25); 0.95 (s, 3H, $\left.\mathrm{H}_{23}\right) ; 0.97$ (s, 3H, H $\left.{ }_{24}\right) ; 1.29$ (d, 4H, H $\left.{ }_{11}, \mathrm{H}_{12}\right) ; 1.38$ (m, 3H, H, $\left.\mathrm{H}_{9}\right) ; 1.45$ (s, 9H, $\left.\underline{H}_{3} \underline{\mathrm{C}}-\mathrm{Boc}\right)$; $1.55\left(\mathrm{t}, 4 \mathrm{H}, \mathrm{H}_{15}, \mathrm{H}_{7}\right) ; 1.65\left(\mathrm{~m}, 6 \mathrm{H}, \mathrm{H}_{13}, 2 \times \mathrm{CH}_{2}, \mathrm{H}_{5}\right) ; 1.69$ (s, 3H H $\left.\mathrm{H}_{30}\right) ; 1.76$ (t, 4H, H $\left.\mathrm{H}_{16}, \mathrm{H}_{1}\right) 1.97$ (t, $\left.3 \mathrm{H}, \mathrm{H}_{18}, \mathrm{H}_{2}\right) ; 2.04$ (s, 3H, H $\mathrm{C}_{3} \mathrm{COO}$ ); 2.47 (m, 15H, $\left.\mathrm{H}_{1}, 7 \times \mathrm{CH}_{2}\right) ; 3.19\left(\mathrm{~m}, 2 \mathrm{H}, \mathrm{CH}_{2}\right) ; 3.32$ (m, 4H, $\left.2 \times \mathrm{CH}_{2}\right) ; 4.48$ (dd, $\left.1 \mathrm{H}, \mathrm{H}_{3}\right) ; 4.59$ (brs, $1 \mathrm{H}, \mathrm{H}_{29 \mathrm{a}}$ ); 4.75 (brs, $\left.1 \mathrm{H}, \mathrm{H}_{29 \mathrm{~b}}\right) ; 5.36(1 \mathrm{H}, \mathrm{NH}) ; 6.86(1 \mathrm{H}, \mathrm{NH})$. ${ }^{13} \mathrm{C}-\mathrm{NMR}\left(\mathrm{CDCl}_{3}, \delta\right): 14.55 ; 16.14 ; 16.22 ; 16.43 ; 18.17 ; 19.46 ; 20.94 ; 20.20 ; 23.68 ; 21.22$ ( $\left.\underline{\mathrm{H}}_{3} \underline{\mathrm{C}}-\mathrm{COO}-\right)$; $25.57 ; 26.42 ; 28.41$ ( $\left.\underline{\mathrm{H}}_{3} \underline{\mathrm{C}}-\mathrm{Boc}\right) ; 29.41 ; 30.91 ; 33.84 ; 34.93 ; 37.12 ; 37.58 ; 37.77 ; 38.39 ; 38.46 ; 39.55$; 39.87; 40.76; 42.42; 46.68; 50.20; 50.57; 53.10; 53.45; 55.48 (4C); 56.73; 57.85; 75.80; 78.79 (Cq-Boc); 80.93; 109.23; 151.04; 156.0 (CO-Boc); 170.90 (H ${ }_{3}$ C-COO-); 176.14 (C-28). HRMS (ESI-MS, $m / z$ ); $[\mathrm{M}+\mathrm{H}]^{+}$: Calcd. for $\mathrm{C}_{47} \mathrm{H}_{80} \mathrm{~N}_{4} \mathrm{O}_{5}$ : 781.1619; Found: 781.6175.

$N$-\{3-[4-(3-aminopropyl)piperazinyl]propyl\}-3-acetylbetulinamide (1c). The $N$-Boc-amino protecting group of compound $\mathbf{1 b}$ was removed using trifluoroacetic acid 10\%/dichloromethane mixture according to the literature [10], resulting in the deprotected analogue 1c. Yield 70\%; m.p. $120{ }^{\circ} \mathrm{C}$. Its spectroscopic data were similar to those of $\mathbf{1 b}$, excepting for the absence of the $\mathrm{N}$-Boc-amino signals. HRMS (ESI-MS, $m / z$ ), [M+H] $]^{+}$: Calcd. for $\mathrm{C}_{40} \mathrm{H}_{72} \mathrm{~N}_{4} \mathrm{O}_{3}$ : 681.0461; Found: 681.5712.

\subsection{Antiplasmodial Assay}

The chloroquine-sensitive 3D7 strain of $P$. falciparum was grown in RPMI (Gibco/Life Technologies, Grand Island, NY, USA) containing $37.5 \mathrm{mM}$ HEPES, supplemented with $7 \mathrm{mM}$ D-glucose, $6 \mathrm{mM} \mathrm{NaOH}, 25 \mathrm{~mL}$ gentamicin sulphate, $2 \mathrm{mM}$ L-glutamine and 10\% human serum albumin. The strains were maintained in human erythrocytes in a gas mixture containing $5 \% \mathrm{O}_{2}, 5 \% \mathrm{CO}_{2}$ and $90 \%$ $\mathrm{N}_{2}$ [24]. The culture was synchronised by $10 \%$ sorbitol treatment [25]. The antimalarial activity was measured using the microdilution technique in vitro. Red cells with parasitemia between 1-2\% and $2 \%$ hematocrit were incubated with the compounds $\mathbf{1}, \mathbf{1 a}-\mathbf{c}$ and $\mathbf{2}, \mathbf{2 a}-\mathbf{c}$ for $48 \mathrm{~h}$. Samples were dissolved in water, dimethylsulfoxide (DMSO) or methanol and serially diluted with the culture medium. To evaluate parasitemia, Giemsa staining and flow cytometric analysis were used. The concentration of the drug required to inhibit parasite growth was determined by comparing the fluorescence incorporated into the treated and untreated cultures (control). The concentration causing $50 \%$ inhibition ( $\mathrm{IC}_{50}$ ) was determined from the drug concentration response curve. Methanol and DMSO were used at the maximum concentration of $0.1 \%$ and did not inhibit parasite growth.

\subsection{Cytotoxicity Assay}

Human embryonic kidney (HEK293T) cells were cultured in surface area $75 \mathrm{~cm}^{2}$ (Greiner Bio-One, Frickenhausen, Germany) vented tissue culture flasks at $37{ }^{\circ} \mathrm{C}$ in a humidified atmosphere containing $5 \% \mathrm{CO}_{2}$ in Dulbecco's modified essential medium (Gibco/Life Technologies, Grand Island, NY, USA) supplemented with $10 \%(\mathrm{v} / \mathrm{v})$ foetal bovine serum, $100 \mathrm{U} / \mathrm{mL}$ penicillin and $100 \mu \mathrm{g} / \mathrm{mL}$ streptomycin. 
After $24 \mathrm{~h}, 50 \mu \mathrm{L}$ of each drug was added with $0.5 \%$ DMSO or methanol to a single well. The cells were incubated with the test drugs for an additional 24 and $48 \mathrm{~h}$ and then harvested with trypsin, gently pelleted by centrifugation and re-suspended in PBS. The cells were stained with dihydroethidium solution $\left(10 \mathrm{mg} / \mathrm{mL}\right.$ in phosphate buffered saline), gently vortexed and incubated for $40 \mathrm{~min}$ at $37{ }^{\circ} \mathrm{C}$ in the dark. Ten thousand gated events were acquired for each sample (FACSCalibur BD and CellQuest software was used for analysis).

\subsection{Infected Erythrocytes: Loading with the Calcium Indicator Fluo4/AM}

Erythrocytes (RBCs) infected by P. falciparum (3D7) at the trophozoite stage were lysed with $10 \mathrm{mg} / \mathrm{mL}$ saponin (in phosphate-buffered saline) in the presence of $20 \mu \mathrm{g} / \mathrm{mL}$ protease inhibitors (pepstatin A, leupeptin, antipain and chymostatin) and benzamidine $(0.5 \mathrm{mmol} / \mathrm{L})$. Erythrocyte membranes were then removed through centrifugation $\left(8700 \mathrm{rpm}\right.$ for $10 \mathrm{~min}$ at $4{ }^{\circ} \mathrm{C}$ ). The parasites were washed three times in buffer $\mathrm{M}\left(116 \mathrm{mM} \mathrm{NaCl}, 5.4 \mathrm{mM} \mathrm{KCl}, 0.8 \mathrm{mM} \mathrm{MgSO}_{4}, 5.5 \mathrm{mM} D\right.$-glucose, $50 \mathrm{mM}$ MOPS, pH 7.3) with $\mathrm{CaCl}_{2}(2 \mathrm{mM})$. The parasites were then re-suspended in the same buffer with Fluo4-AM $(5 \mu \mathrm{M})$ probenecid $(1.8 \mathrm{mM})$, an inhibitor of organic anion transport (to prevent dye sequestration and release), $20 \mathrm{mg} / \mathrm{mL}$ protease inhibitors (pepstatin $\mathrm{A}$, leupeptin, antipain and chymostatin) and benzamidine $(0.5 \mathrm{mmol} / \mathrm{L})$ for $50 \mathrm{~min}$ at $37{ }^{\circ} \mathrm{C}$. The parasite suspension was then washed three times with buffer M. Spectrofluorimetric measurements were performed in a Shimadzu RF-5301 PC instrument at $37{ }^{\circ} \mathrm{C}$ with isolated $P$. falciparum (3D7) parasites $\left(10^{8}\right.$ cells $\left.\mathrm{mL}^{-1}\right)$ incubated with MOPS buffer in a $1 \mathrm{~mL}$ cuvette. Compound $2 \mathrm{c}(100 \mu \mathrm{M})$ and THG $(10 \mu \mathrm{M})$ were added during time course experiments, and excitation/emission wavelengths were adjusted to 505/530 nm for Fluo4-AM. Methanol (0.05\%) was used as a control. Addition of the detergent digitonin induced the maximum increase in calcium that was abolished by addition of the calcium chelator EGTA.

\subsection{Statistical Analysis}

Student's test was chosen for comparisons between two groups, whereas repeated ANOVA measures were used for comparisons among more than two groups. The results are expressed as the mean \pm SEM of at least three individual experiments. $P<0.05$ was considered a statistically significant difference. GraphPad Prism software (San Diego, CA) was used for all statistical tests.

\section{Conclusions}

In this study, we synthesized new piperazinyl derivatives of betulinic and ursolic acids considering the previous active designed compounds. The best compounds, $\mathbf{1 c}$ and $\mathbf{2 c}$, showed $\mathrm{IC}_{50}$ values in the range of 175 to $220 \mathrm{nM}$ against the $P$. falciparum chloroquine-sensitive 3D7 strain, and they are considered non-toxic (SI > $10 \mu \mathrm{M})$. The observed changes in calcium homeostasis demonstrated that ursolic acid derivative 2c led to an increase in intracellular ion concentrations in P. falciparum. In conclusion, compound $\mathbf{2 c}$ is a new potent antimalarial prototype that disrupts Plasmodium calcium homeostasis. 


\section{Acknowledgments}

This work was supported by grants and financial support from Instituto Nacional de Ciência e Tecnologia para Inovação Farmacêutica (INCT-if, Brazil), Conselho Nacional de Desenvolvimento Científico e Tecnológico (CNPq-Brazil), Coordenação de Aperfeiçoamento de Pessoal de Nível Superior (CAPES-Brazil), Fundação de Amparo à Pesquisa do Estado de São Paulo (FAPESP, Brazil) and Fundação de Amparo à Pesquisa do Estado do Rio Grande do Sul (FAPERGS, Brazil). Laura N. Cruz and Miriam S. Moraes received a FAPESP fellowship. We also thank Norberto Peporine Lopes (USP-RP, Brazil) for the HRMS analyses and Tecnovin do Brasil, RS, for supplying the apple material.

\section{References}

1. WHO. World Malaria Report 2011. Available online: http://www.who.int/malaria/ world_malaria_report_2011/en/(accessed on 11 August 2012).

2. Mita, T.; Tanabe, K.; Kita, K. Spread and evolution of Plasmodium falciparum drug resistance. Parasitol. Int. 2009, 58, 201-209.

3. White, N.J. Qinghaosu (artemisinin): The price of success. Science 2008, 320, 330-334.

4. Frearson, J.A.; Wyatt, P.G.; Gilbert, I.H.; Fairlamb, A.H. Target assessment for antiparasitic drug discovery. Trends Parasitol. 2007, 23, 589-595.

5. Krettli, A.U.; Adebayo, J.O.; Krettli, L.G. Testing of natural products and synthetic molecules aiming at new antimalarials. Curr. Drug Targets 2009, 10, 261-270.

6. Steele, J.C.P.; Warhurst, D.C.; Kirby, G.C.; Simmonds, M.S.J. In vitro and in vivo evaluation of betulinic acid as an antimalarial. Phytother. Res. 1999, 13, 115-119.

7. Ziegler, H.L.; Franzyk, H.; Sairafianpour, M.; Tabatabai, M.; Tehrani, M.D.; Bagherzadeh, K. Erythrocyte membrane modifying agents and the inhibition of Plasmodium falciparum growth: Structure-activity relationships for betulinic acid analogues. Bioorg. Med. Chem. 2004, 12, 119-127.

8. Liu, J. Oleanolic acid and ursolic acid: Research perspectives. J. Ethnopharmacol. 2005, 100, 92-94.

9. Yogeeswari, P.; Sriram, D. Betulinic acid and its derivatives: A review on their biological properties. Curr. Med. Chem. 2005, 12, 657-666.

10. Gnoatto, S.C.B.; Susplugas, S.; Dalla Vechia, L.; Ferreira, T.B.; Dassonville-Klimpt, A.; Zimmer, K.R.; Demailly, C.; Da Nascimento, S.; Guillon, J.; Grellier, P.; et al. Pharmacomodulation on the 3-acetylursolic acid skeleton: Design, Synthesis, And biological evaluation of novel $\mathrm{N}$-\{3-[4-(3-aminopropyl)piperazinyl]propyl\}-3-O-acetylursolamide derivatives as antimalarial agents. Bioorg. Med. Chem. 2008, 16, 771-782.

11. Girault, S.; Grellier, P.; Berecibar, A.; Maes, L.; Lemiere, P.; Mouray, E. Antiplasmodial activity and cytotoxicity of bis-, tris-, and tetraquinolines with linear or cyclic amino linkers. J. Med. Chem. 2001, 44, 1658-1665.

12. Ryckebusch, A.; Deprez-Poulain, R.; Debreu-Fontaine, M.A.; Vandaele, R.; Mouray, E.; Grellier, P. Parallel synthesis and anti-malarial activity of a sulfonamide library. Bioorg. Med. Chem. Lett. 2002, 12, 2595-2598. 
13. Beraldo, F.H.; Almeida, F.M.; da Silva, A.M.; Garcia, C.R.S. Cyclic AMP and calcium interplay as second messengers in melatonin-dependent regulation of Plasmodium falciparum cell cycle. J. Cell Biol. 2005, 170, 551-557.

14. Beraldo, F.H.; Mikoshiba, K.; Garcia, C.R.S. Human malarial parasite, Plasmodium falciparum, displays capacitative calcium entry: 2-Aminoethyl diphenylborinate blocks the signal transduction pathway of melatonin action on the P. falciparum cell cycle. J. Pineal Res. 2007, 43, 360-364.

15. Garcia, C.R.S.; Azevedo, M.F.; Wunderlich, G.; Budu, A.; Young, J.A.; Bannister, L. Plasmodium in the postgenomic era: New insights into the molecular cell biology of malaria parasites. Int. Rev. Cell Mol. Biol. 2008, 266, 85-156.

16. Koyama, F.C.; Chakrabarti, D.; Garcia, C.R.S. Molecular machinery of signal transduction and cell cycle regulation in Plasmodium. Mol. Biochem. Parasitol. 2009, 165, 1-7.

17. Traore-Keita, F.; Gasquet, M.; Di Giorgio, C.; Ollivier, E.; Delmas, F.; Keita, A.; Doumbo, O.; Balansard, G.; Timon-David, P. Antimalarial activity of four plants used in traditional medicine in Mali. Phytother. Res. 2000, 14, 45-47.

18. Duker-Eshun, G.; Jaroszewski, J.W.; Asomaning, W.A.; Oppong-Boachie, F.; Brogger Christensen, S. Antiplasmodial constituents of Cajanus cajan. Phytother. Res. 2004, 18, 128-130.

19. Barea, C.; Pabón, A.; Galiano, S.; Pérez-Silanes, S.; Gonzalez, G.; Deyssard, C.; Monge, A.; Deharo, E.; Aldana, I. Antiplasmodial and leishmanicidal activities of 2-cyano-3-(4-phenylpiperazine1-carboxamido) quinoxaline 1,4-dioxide derivatives. Molecules 2012, 17, 9451-9461.

20. Thibeault, D.; Gauthier, C.; Legault, J.; Bouchard, J.; Gagné, L.; Pichette, A. Synthesis and cytotoxicity of lupane-type triterpenoid glyceryl esters. Bioorg. Med. Chem. Lett. 2012, 22, 4735-4739.

21. Urban, M.; Vlk, M.; Dzubak, P.; Hajduch, M.; Sarek, J. Cytotoxic heterocyclic triterpenoids derived from betulin and betulinic acid. Bioorg. Med. Chem. Lett. 2012, 20, 3666-3674.

22. Gazarini, M.L.; Thomas, A.P.; Pozzan, T.; Garcia, C.R.S. Calcium signaling in a low calcium environment: How the intracellular malaria parasite solves the problem. Cell Biol. 2003, 161, 103-110.

23. Varotti, F.P.; Beraldo, F.H.; Gazarini, M.L.; Garcia, C.R.S. Plasmodium falciparum malaria parasites display a THG-sensitive $\mathrm{Ca}^{2+}$ pool. Cell Calcium 2003, 33, 137-144.

24. Trager, W.; Jensen, J.B. Human malaria parasites in continuous culture. Science 1976, 193, 673-675.

25. Lambros, C.; Vanderberg, J.P.J. Synchronization of Plasmodium falciparum erythrocytic stages in culture. Parasitology 1979, 65, 418-420.

Sample Availability: Samples of the compounds are available from the authors.

(C) 2012 by the authors; licensee MDPI, Basel, Switzerland. This article is an open access article distributed under the terms and conditions of the Creative Commons Attribution license (http://creativecommons.org/licenses/by/3.0/). 